Bull. Mater. Sci., Vol, 2, Number 2, May 1980, pp. 127-133. Printed in India.

\title{
Growth of single crystals of some complex salts in silica gels
}

\author{
M S JOSHI, P MOHAN RAO and A V ANTONY \\ Department of Physics, Sardar Patel University, Vallabh Vidyanagar 388 120, \\ India
}

MS received 1 January 1980

\begin{abstract}
Single crystals of ammonium nickel sulphate, potassium nickel sulphate, ammonium alum and potassium alum are grown in sodium-metasilicate gels. The method of gel preparation and growth procedure are described. Both single diffusion and double diffusion methods are used. Studies on nucleation and characterisation of crystals are also reported. Crystals grown are illustrated.
\end{abstract}

Keywords. Single crystals; complex salts; silica gels; gel method.

\section{Introduction}

Substantial data is available in literature (Henisch 1970; Banks et al 1973; Cho et al 1977; Joshi et al 1978; Shiojiri et al 1978) on growth mechanism, characteristics and nucleation of crystals in gels. Although the technique is old, Henisch et al (1965) have thrown light on the preparation of single crystals in gels. The technique is quite interesting in that it could be used to grow ionic, organic and metallic crystals at ambient temperatures. An additional advantage is that the method is simple and inexpensive.

Large single crystals of complex salts are usually crystallised from aqueous solutions. This method requires accurate temperature regulation. The present paper deals with a method for preparation of single crystals of some complex salts soluble in water.

In gel growth of crystals, generally two or more species are allowed to react to form the desired solid product. The reaction waste product formed will greatly influence further growth of the crystals. Recently, gel technique was used to grow crystals of water soluble salts by reducing their solubility (Glockber and Soest 1969; Brezina and Havrankova 1971). In the present study, aqueous solutions of two salts are brought together by diffusion through silica gel to form a relatively less soluble complex salt in crystalline form. No reaction waste material is formed. Single crystals of ammonium nickel sulphate, potassium nickel sulphate, ammonium aluminium sulphate and potassium aluminium sulphate are grown by this method and, optimum conditions for their growth are reported. 


\section{Experimental}

Silica gel was prepared by mixing an aqueous solution of sodium metasilicate (sp. gr. 1.04) with $1 \mathrm{~N}$ sulphuric acid. Both single diffusion and double diffusion methods were employed. A schematic representation of these two methods are illustrated in figures 1 (a) and 1 (b). In single diffusion experiments with test tubes, one of the reacting solutions was incorporated in the gel. After the gel was set, the other solution was added slowly above the gel. In double diffusion experiments, both the solutions were poured slowly into the two limbs of U-tubes after the gel was set. AnalaR grade $\mathrm{H}_{2} \mathrm{SO}_{4},\left(\mathrm{NH}_{4}\right)_{2} \mathrm{SO}_{4}, \mathrm{~K}_{2} \mathrm{SO}_{4}$, $\mathrm{NiSO}_{4} \cdot \mathrm{H}_{2} \mathrm{O}$ and $\mathrm{Al}_{2}\left(\mathrm{SO}_{4}\right)_{3}$ were used.

\section{Observations and discussion}

Table 1 lists various complex salt crystals grown in gels, the method employed and the optimum conditions for their growth. Figure 2 is a photograph of crystals of ammonium nickel sulphate grown by this method. They are bluishgreen in colour. It was found that quite transparent crystals of ammonium nickel sulphate with definite geometrical shapes grow in gel, only when nickel sulphate is incorporated in the gel (single diffusion experiments). By inter-

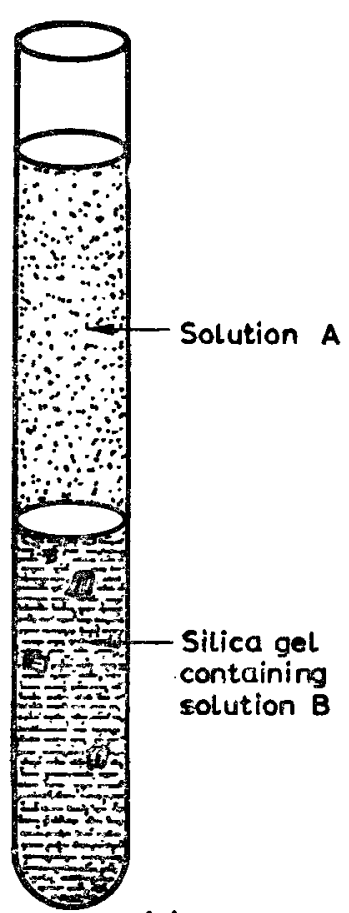

(a)

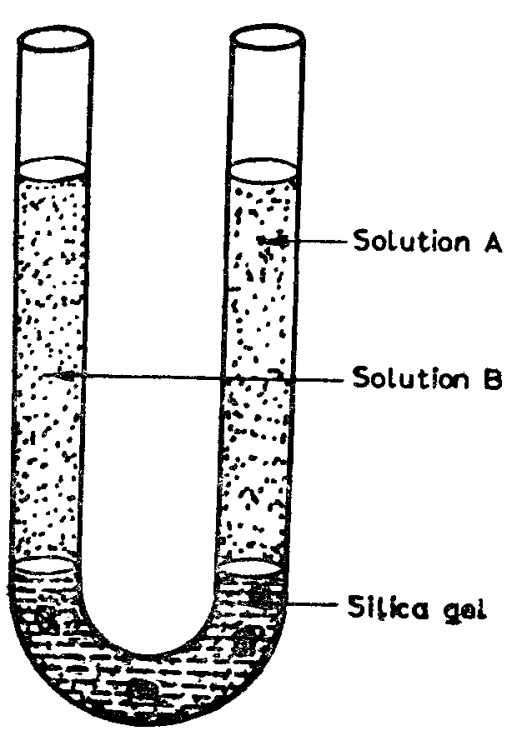

(b)

Figure 1. Schematic representation of (a) Single diffusion and (b) Double diffusion methods. 
Growth of single crystals in silica gels

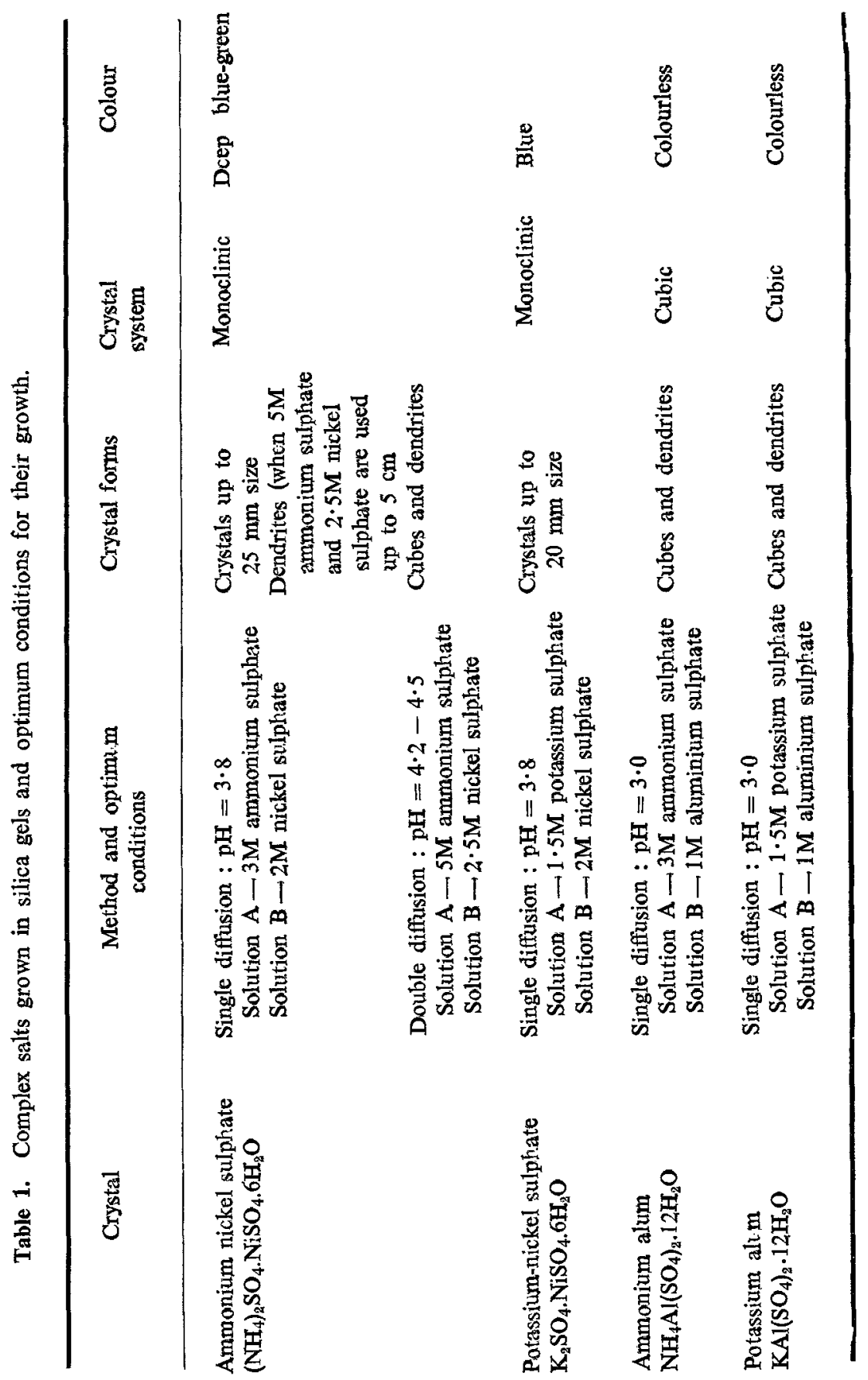


changing the two solutions it is found that nucleation takes place only at the interface and no nuclei are formed deep inside the gel. Increase in concentration of any of the solutions or both leads to growth in dendritic form. Some of the crystals in dendritic form are shown in figure 3. Decrease in concentration reduces nucleation. When concentrations of solutions are very low, sufficient supersaturation required for growth of complex salt crystals is not achieved at and hence no nucleation takes place.

In potassium nickel sulphate, no growth takes place in dendritic form, even when saturated solutions of potassium sulphate and nickel sulphate are used. This may be due to the lower solubility of potassium sulphate compared to ammonium sulphate. Some of the crystals of potassium-nickel sulphate grown by this method are shown in figure 4 .

Crystals of ammonium alum and potassium alum were also grown by the same method. Photographs of ammonium alum and potassium alum crystals grown are shown in figures 5 and 6 respectively. Alum crystals were also found to grow in dendritic form when higher concentrations of the reacting solutions were used. Here also, quite transparent crystals are obtained in single diffusion experiments, when aluminium sulphate solution was incorporated in silica gel and ammonium or potassium sulphate solution was added above the gel.

In the case of growth of the crystals from aqueous solutions, when the two salt solutions are mixed, large nucleation occurs. Nucleation is sufficiently low in the present method because of the gel media.

Generally, in experiments with U-tubes when two solutions are allowed to react in gel, nucleation occurs and is large in the central regions of the gel column. In the present study, it was found that nucleation is larger at the gel-solution interface, in both limbs of U-tube than at the central region. This, we believe, is due to higher solubility of the complex salt. If concentrations of both solutions are low, both of them diffuse through gel until they come in direct contact of each other at the two gel-solution interfaces in the two limbs of the U-tube and, nucleation takes place there itself. No nucleation is formed inside the gel column, since the required supersaturation is not achieved there. However, increase in concentration of ammonium sulphate and nickel sulphate resulted in nucleation in the central region of gel column also.

Effects of pH, gel ageing and gel density on nucleation and quality of crystals were also studied. It was found that increase in $\mathrm{pH}$, gel ageing and gel density reduces the number of nuclei and transparency of crystals.

Crystals grown by the above method were identifed by chemical analysis. Surfaces of crystals grown are very smooth. Crystals possess different morphology.

\section{Conclusion}

Growth of complex salts by gel method is a powerful supplement to the use of silica gels in growing crystals of water-soluble salts.

Large, transparent, single crystals of ammonium nickel sulphate, potassium nickel sulphate, ammonium alum and potassium alum of different morphology were grown in silica gels. 

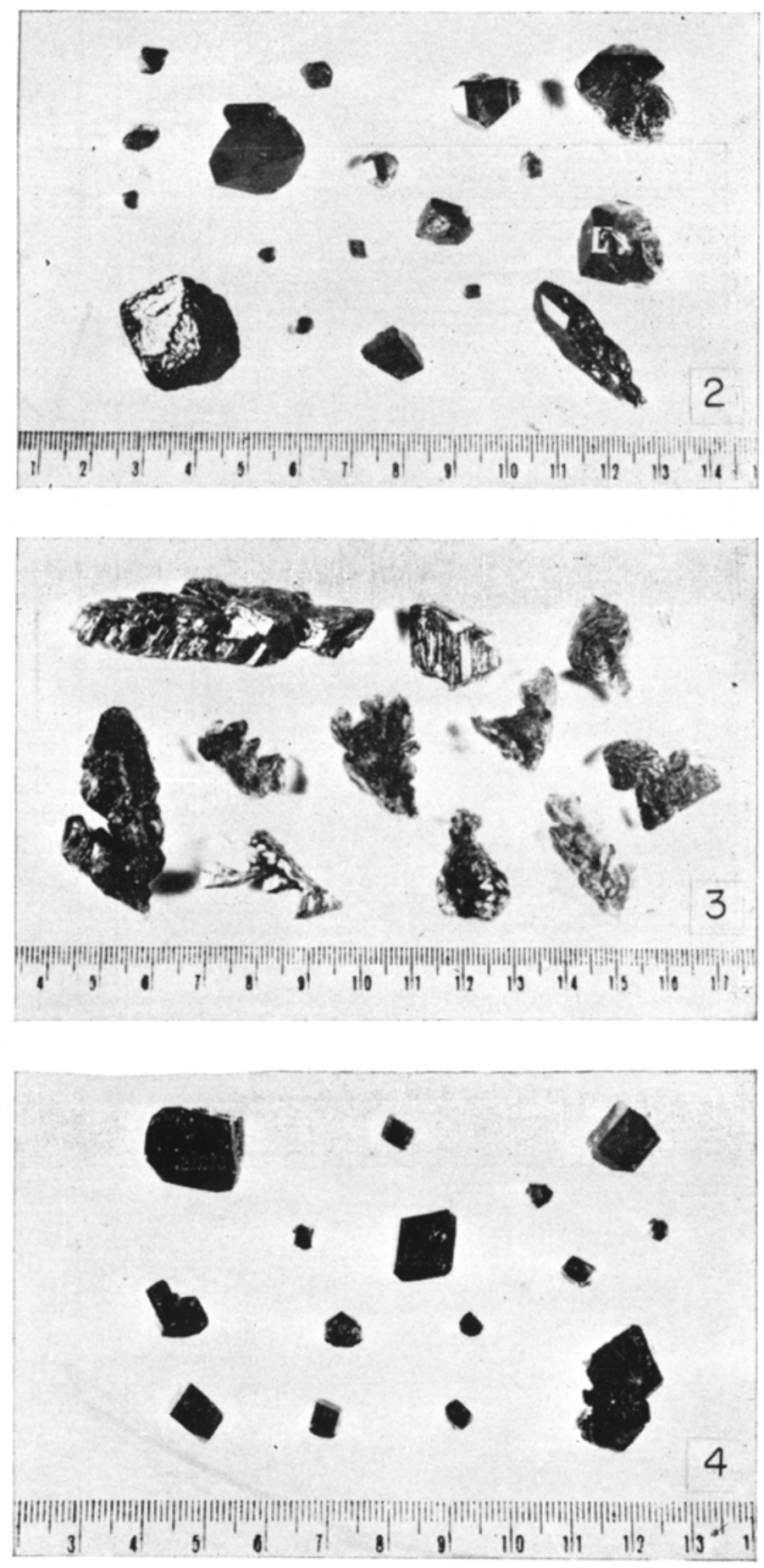

Figures 2-4. 2. Ammonium nickel sulphate single crystals. 3. Dendritic crystals of ammonium nickel sulphate. 4. Potassium-nickel sulphate single crystals. 

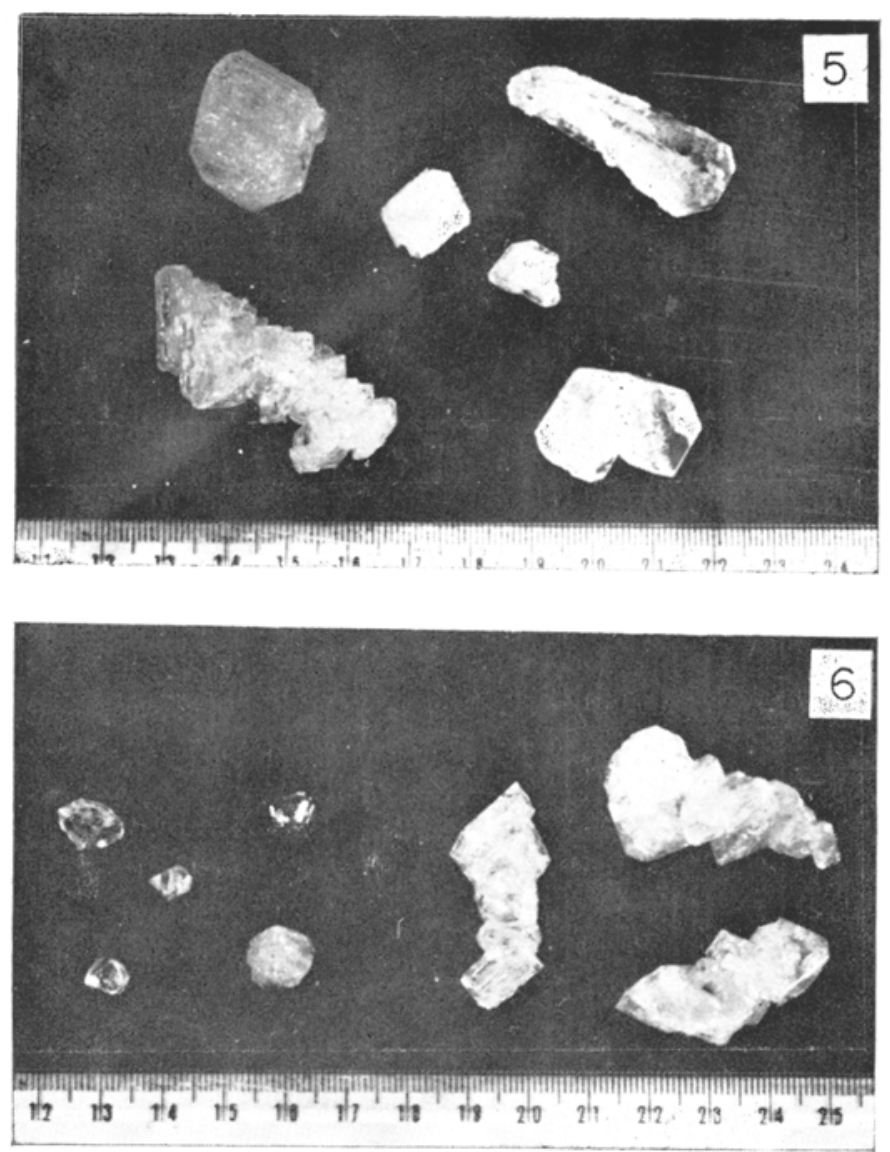

Figures 5,6. 5. Ammonium alum single crystals. 6. Potassium alum single crystals. 


\section{Acknowledgement}

PMR thanks the University Grants Commission, New Delhi, for financial assistance and to the Management of SDM College, Ujire, for study leave.

\section{References}

Banks E, Chianelli R and Pintchovsky F 1973 J. Cryst. Growth 18185

Brezina B and Havrankova M 1971 Mater. Res. Bull. 6537

Cho S A, Gomez J A, Camisotti R and Ohep J C 1977 J. Mater. Sci. 12816

Glockber D A and Soest J E 1969 J. Chem. Phys. 51 3143-

Henisch H K 1970 Crystal growth in gels (Pennsylvania : University Press)

Henisch H K, Dennis J and Honoka J I 1965 J. Phys. Chem. Solids 26439

Joshi M S and Antony A V 1978 J. Mater. Sci. 13939

Shiojiri M, Kaito C, Saito Y, Murakami M and Kawamoto J 1978 J. Cryst. Growth 4361 